\title{
Artigas
}

Ensino

e formação

profissional

\section{O estágio no ensino do jornalismo: a experiência da Universidade Federal de Goiás}

\section{Francisco Eduardo Ponte Pierre*}

\section{Resumo}

Este artigo, após um rápido sobrevôo dos sistemas internacionais, apresenta as experiências de estágio de jornalismo da Universidade Federal de Goiás no contexto da legislação brasileira. Ênfase especial é dada à experiência mais recente e à sua importância no ensino do jornalismo.

Palavras-chave: estágio, ensino, jornalismo.

\section{Os sistemas internacionais de estágio de jornalismo}

Na maioria dos paises mais importantes, entre os quais aqueles, França e Estados Unidos, que mais influência exerceram na constituição de nosso modelo de jornalismo, tem vigência a instituição do estágio dos estudantes nas empresas jornalísticas.

* Doutor em Ciências da Informação pela Universidade de Paris 2 e professor titular da Faculdade de Comunicação e Biblioteconomia da UFG. 
Na França, a Comissão de Coordenação do Ensino do Jornalismo, ("Feuillets du CFPF", p.5), estabeleceu três tipos de estágios:

- Os estágios "de descoberta" ou "de sensibilização" não podem ultrapassar duas semanas. Eles visam completar a informação dos estudantes sobre a profíssão, a empresa e o meio profissional. Não podem ocasionar o desempenho de tarefas de produção e não geram qualquer tipo de remuneração.

- Os estágios de produção durante os esiudos têm uma duração mínima de um e máxima de três meses. Desenvolvidos preferencialmente durante as férias, eles tềm natureza de substituição profissional, constituem trabalho efetivo, dando direito a uma remuneração estabelecida por convenção coletiva e a um seguro contra riscos e acidentes.

- Os estágios profissionais ao término dos estudos não têm duração pré-determinada. São os estágios propriamente ditos para os quais a convenção coletiva de trabalho prevê o pagamento de um piso profissional.

Os dois sistemas de treinamento da Inglaterra guardam reduzidas semelhanças com o modelo anterior.

O primeiro sistcma, pre-entry training, consiste em um ano de universidade scguido de um período de treinamento no lugar de trabalho (encargo do empregador), durando de seis meses a dois anos(...) O segundo sistema é o treinamento on the job, especificamente: os estudantes são empregados nos jornais e passam por um período intensivo de cursos em bloco ministrados pela Universidade. É o post-entry ou direct entry e depois de um ano neste sistema os estudantes fazem os exames da NCTJ ( National Council of the Training of Journalists" (De Freitas, 1992, p. 70s.).

\section{Nos Estados Unidos}

todas as formas de treinamento, estágio, free-lancing, são estimulados. Cerca de 50 por cento dos alunos de graduação e 80 por cento dos alunos de pós-graduação, fazem algum tipo de estágio em veículos do mercado. Além disso, a maioria das escolas possuem veículos próprios, totalmente produzidos pelos 
alunos. No currículo, entre as disciplinas optativas, consta 0 estágio com crédito (internship). Por força dos sindicatos há algumas regras que regulam os estágios, mas nunca de forma a proibi-los ou discriminá-los" (Kuscinski, 1992, p.162).

\section{0 sistema brasileiro de estágio de jornalismo}

\subsection{O estágio profissional de jornalismo}

A regulamentação da profissão de jornalista, estabelecida pelo Decreto-lei n. 972, de 17 de outubro de 1969, dispõe que o exercício da profissão de jornalista requer " prévio registro" no Ministério do Trabalho. Este registro deverá ser feito mediante "diploma de curso superior de jornalismo" e, até dezembro de 1978, " declaração de cumprimento de estágio em empresa jornalística".

O estágio em empresa jornalística, cuja realização deveria ser precedida de registro no Ministério do Trabalho, tinha duração de pelo menos um ano. $O$ bacharel em jornalismo e também o aluno do último ano do curso poderiam ser contratados como estagiários.

A Lei n. 6.612-de 7 de dezembro de 1978 - altera o Decreto-lei n. 972 e, entre outras disposições, elimina o estágio profissional, condição do registro e do exercício legal do jornalismo.

O Decreto n. 83.284 - de 13 de março de 1979 - é mais radical e diz mesmo que "constitui fraude a prestação de serviços profissionais gratuitos, ou com pagamentos simbólicos, sob pretexto de estágio ..." (Art. 19).

Encerra-se aí a experiência brasileira de estágio profissional de jornalismo.

\section{2 estágio escolar, estudantil ou curricular}

Para " propiciar a complementação do ensino e da aprendizagem", a legislação brasileira ( Lei n. 6.494 - de 7 de dezembro de 1977) faculta às empresas e aos órgãos públicos aceitar, como estagiários, os estudantes de estabelecimentos de ensino 
superior, profissionalizante, supletivo ou de $2^{\circ} \mathrm{grau}$, desde que tenham condições de proporcionar experiência prática na linha de formação.

Estão contempladas como estágio “as atividades de aprendizagem social, profissional e cultural, proporcionadas ao estudante pela participação em situações reais de vida e trabalho" (Decreto n. 87.497 - de 7 de dezembro de 1977). Compete à escola inserir o estágio em sua programação didático-pedagógica.

Este estágio não gera vínculo empregatício. Para sua caracterização é necessária a existência de instrumento jurídico, periodicamente reexaminado pelas partes, que estabeleça as condições de sua realização.

Um seguro de acidentes pessoais está previsto em favor do estudante que, se não tem garantida, nas empresas privadas, qualquer remuneração, está infenso à cobrança de despesas para a realização do estágio.

Nos órgãos da administração pública, o estudante, por força da Instrução Normativa n. 7 - de 26 de maio de 1992 - a título de bolsa de estágio, perceberá importância mensal, de acordo com o plano de classificação dos cargos federais.

\section{0 estágio curricular de jornalismo: A experiência da UFG}

\subsection{Antecedentes}

"O fortalecimento das escolas e o fim dos estágios", trabalho apresentado por uma delegação, composta por alunos, no XXVI Congresso Nacional de Jornalistas Profissionais, em junho de 1976, em Cúritiba, representou a posição do Departamento de Comunicação Social da UFG frente ao estágio profissional obrigatório.

O documento registra como desvantagens daquele estágio: "o enfraquecimento da classe universitária", "a baixa remuneração", "a debilitação do mercado de trabalho", "a marginalização do estagiário dentro da empresa" e "o tempo de duração". Como resultado, diz o documento, "de agente 
complementador de experiência e treinador, o estágio pode passar a se constituir em um instrumento altamente inibidor da criatividade e da renovação dos conhecimentos práticos e teóricos".

Diante disso, o documento pede a "descaracterização" ou mesmo o "extermínio dessa exigência", mesmo porque, acrescenta, a legislação trabalhista já prevê o estágio probatório de 90 dias e "por outro lado, o fortalecimento da estrutura das escolas, com a melhora de seu quadro de pessoal e dos seus equipamentos, podem muito bem suprir esta falha que o estágio diz preencher".

O fim do estágio obrigatório foi sentido pelas escolas, pelos alunos e pela corporação dos jornalistas como emancipação de uma menoridade, como liberalização política, como abolição de uma corvéia e de um elemento falseador do mercado de trabalho.

A leitura redutora da Lei n. 6.612 e do Decreto n. 83.284 decorreu assim quase natural e espontaneamente como uma ques.-. tão de "consciência possível".

Na Universidade Federal de Goiás, só em 1993, começa-se a entender que daquelas normas não se deve inferir que todo e qual.quer estágio, que não implique prestação de serviços profissionais, esteja abolido, sobretudo aqueles que pudessem ser abrigados pela Lei 6.494 .

Dessa nova compreensão originou-se a proposta da chefia do Departamento à Organização Jaime Câmara/ O Popular, maior grupo de comunicação de Goiás, de que oferecesse aos alu-nos do último ano de jornalismo "oficinas" que permitissem aos alunos o contato com o meio e a realidade profissionais, dentro de uma programação que contemplasse o conhecimento prático das diversas etapas do processo jornalístico. Os participantes das " oficinas " teriam sua participação registrada, com o reconhecimento das horas dedicadas sob a forma de "atividades complementares" para fins de integralização do currículo (Of. n. 053/93).

Surgiu, logo depois, dessa iniciativa, com a aprovação da $\mathrm{Co}$ ordenação do Curso de Jornalismo e do Departamento de Comunicação o Programa de Estágio O Popular. 


\subsection{0 estágio de jornalismo em O Popular}

O Programa de Estágio - O Popular, conveniado entre a Organização Jaime Câmara e o Departamento de Comunicação da Universidade Federal de Goiás tem como objetivos especificos:

proporcionar a complementação da formação acadêmica dos estudantes de jornalisirio; proporcionar aos acadêmicos oportunidade para desenvolver os conhecimentos adquiridos durante sua formação; proporcionar a $O$ Popular uma importante fonte de recrutamento de futuros profissionais; obter a conseqüente melhoria do mercado profissional de jornalismo; proporcionar uma maior integração Empresa-Escola-Comunidade.

O estágio, destinado aos alunos do último ano de jornalismo, desenvolve-se durante cinco dias da semana com carga de quatro horas diárias. A empresa oferece ao estagiário bolsaauxílio de $50 \%$ do salário mínimo, seguro de vida contra acidentes pessoais e vale-transporte.

Como programa de estágio

nos primeiros dias os estagiários se dedicarão à fase do treinamento introdutório conhecendo a empresa e familiarizando-se com a redação, seu sistema de funcionamento e estrutura organizacional. Uma vez concluído o treinamento introdutório, os estagiários serão encaminhados para as editorias para acompanhamento dos repórteres na execução de suas tarefas. Todas as atividades realizadas pelos estagiários, inclusive a redação de matérias, serão analisadas pelos editores de cada área, com avaliação final do final do supervisor do estágio. As matérias produzidas pelos estagiários não são destinadas a publicação $\mathrm{e}$ só poderão ser publicadas excepcionalmente, por solicitação do supervisor do estágio para fins de motivação do estagiário, com seu conhecimento prévio e crédito pelo trabalho.

\subsection{A reação sindical}

A formalização do programa de estágios foi precedida de discussões e consultas, com a direção do Sindicato dos Jornalistas Profissionais do Estado de Goiás, que não resultaram em 
acordo. Com o início dos estágios, no segundo semestre de 1993, veio a reação sindical.

Através de uma "Nota de Protesto" - de 08 de setembro de 1993 - , de matérias em seu órgão oficial de divulgação Chamada - de fevereiro de 1994 e de setembro de 1995 - e de algumas ações diretas - que não lograram êxito nem no Ministério do Trabalho e nem na Reitoria da Universidade -, o Sindicato dos Jornalistas tem criticado e reclamado o fim do " pseudo-estágio “.

Substancialmente o sindicato tem atacado o " servilismo " do Departamento de Comunicação, a " cessão de mão-de-obra a preço vil (meio salário mínimo mensal)" e, sobretudo opõe-se ao "pseudo-estágio" porque "é ilegal e fere frontalmente a legislação".

\section{$4 O$ estágio legal, necessário, proveitoso e perfectível}

\subsection{O estágio legal}

"Constitui fraude a prestação de serviços profissionais gratuitos, ou com pagamentos simbólicos, sob pretexto de estágio, bolsa de estudo, bolsa de complementação, convênio ou qualquer outra modalidade, em desrespeito à legislação trabalhista e a este regulamento".

É o que diz o art. 19 do Decreto n. 83.284 - de 13 de março de 1979.

Colocando a frase em ordem direta, verifica-se que ela tem por sujeito a expressão "a prestação de serviços profissionais gratuitos ou com pagamentos simbólicos" . Dela, "prestação", sujeito da frase, é que se predica "constituir fraude".

A prestação de serviços profissionais gratuitos ou com pagamentos simbólicos está pois proibida ainda que, para escamotear a lei, se faça reclamação de instrumentos respeitáveis tais como estágio, bolsa de estudo, bolsa de complementação, convênio etc. Dizer porém que qualquer estágio encontra-se proibido pelo Decreto n. 83.284 corresponde a afirmar que uma empresa jornalística não poderia assinar convênio algum, de qualquer natureza, com uma escola de comunicação ou que algo pode ser

Comun. inf., v.1, n. 1, p. 120-132, jan.jjun. 1998 
impedido de ser feito, em sistema democrático, independentemente da força da lei.

Estágios que não envolvam " prestação de serviços profissionais" não estão pois compreendidos pelo Decreto $\mathrm{n}$. 83.284. Destes estágios cuida uma outra legislação que se estende a todo o universo dos estabelecimentos escolares. Desta conclusão comunga a Secretaria de Fiscalização do Ministério do Trabalho, que decidiu pela legalidade do estágio, através do Parecer \$ETIF/CANOR/ 14/95, ratificado pelo Parecer SETIF/CAJ/ 001/96, ambos exarados no processo n. 46.208.008.028/93.

As forças que acreditaram interpretar a seu favor o Decreto n. 83.284 não atentaram para o fato de que o conceito de estágio não é unívoco, demonstrando assim pouca experiência de analogia. O estágio em O Popular não difere toto coelo, saindo-se do nome e permanecendo-se na coisa, dos programas de treinamento promovidos pelos grandes jornais de São Paulo.

\subsection{O estágio legitima a regulamentação da profissão}

À medida em que uma empresa jornalística, para integrar seus quadros, decida por recrutá-los entre os formandos do curso de jornalismo, proporcionando-lhes um programa de treinamento, fica fortalecido seu compromisso com a regulamentação da profissão. Isto é tão mais importante enquanto, rejeitando a alternativa ilegal mas não de todo incomum, esta empresa renuncia conseqüentemente - sem o que o estágio perderia qualquer substância - a compor suas páginas com a "prestação de serviços profissionais" dos alunos dos primeiros anos de escola.

\subsection{O estágio aproxima escola e empresa}

Ainda que, por processo mimético, possam existir, no Brasil e no mundo, escolas de comunicação independentemente de um ambiente empresarial forte, não é esta a regra em sociedades democráticas. 
As escolas de jornalismo nasceram com o desenvolvimento da indústria, às vezes por iniciativa dos próprios empresários que compreenderam os ganhos que aufeririam com o recrutamento de uma mão de obra educada, já treinada e com formação ética, técnica e estética.

Como demonstra José Marques de Melo ( p. 21 ss.), o jornalismo constitui-se em "processo social de natureza industrial". Assim, é sobretudo para atuar nas empresas, microempresas e organizações modernas que as escolas de jornalismo formam seus alunos. Não negamos aqui a existência e a grande importância social dos chamados jornalistas comunitários ou populares. Entretanto, não apresentam eles, no exercício de seu jornalismo, a exclusividade e a especificidade de atuação que os diferenciam de outros atores sociais e que caracterizam o profissionalismo. Ademais, deles, como se sabe, não se exige diploma ou formação acadêmica e portanto não constituem a clientela primária e principal das escolas de jornalismo.

O estágio compromete e insere a empresa no processo de formação do estudante. Ele gera processos de encontro e pode constituir-se em fórum de discussão da formação acadêmica. Nessa aproximação, a escola poderá fazer compreender que a preparação do aluno para atuar na empresa concilia-se com uma formação mais integral e que disso a escola não abrirá inão.

A aproximação será mais feliz na medida em que a empresa respeitar as preocupações críticas da escola e em que se sentir assegurada de que a escola aceita sua existência dentro da economia de mercado e de que é bem-vinda sua comparticipação na formação do aluno.

Que esta aproximação com as empresas pode e deve ser feita, já o descobriram, apesar das tensões e dos conflitos, os jornalistas que nelas trabalham e nelas exercem suas funções, em beneficio do interesse público.

\subsection{0 estágio é essencial no currículo do curso}

O estágio é fundamental para o currículo, entendido como processo sistemático, orgânico e evolutivo, de conhecimentos

Comun. inf., v.1, n. 1, p. 120-132, jan.jun. 1998 
e práticas que se percorre para realizar um projeto de formação.

Acreditou-se, durante uma certa conjuntura, que projetos experimentais e órgãos laboratoriais, sustentados por uma infraestrutura operacional adequada, pudessem dispensar o treinamento prático nas empresas. Não apenas em razão do $g{ }^{m}$ tecnológico inevitável que separa o mundo da produção do mun do da universidade, essa concepção começa a desvanecer-se.

Estágios curriculares e extracurriculares e projetos experimentais "podem até caminhar lado a lado em seus próprios espaços", "são esferas distintas". O estágio configura-se como produção de saber técnico, o contato primeiro do aluno com a organização empresarial. O projeto experimental, como produção científica fundamentada nos conhecimentos apreendidos" (Targino, 1995, p. 26 s).

Diferentemente de Karam ( 1995 , p.3 ) que considera sua defesa "exercício de oportunismo", Palácios (1993, p. 13s ) reclama mesmo a volta do estágio profissional. Diz ele que

a tentativa de substituir o estágio profissional por tais práticas laboratoriais não só resulta impossível, mas também extremamente nefasta. (...) o estágio profissional e as práticas laboratoriais devem ser concebidas como complementares e jamais como alternativas". Com a inexistência do estágio, para ele, "os próprios laboratórios acabaram sendo encarados como recriação, in vitro, das condições que efetivamente existem no mercado de trabalho". "Este tipo de concepção do lugar das práticas laboratoriais coloca uma série de problemas, dentre as quais ... o Artificialismo, a Emulação Estreita e o Reboquismo".

\subsection{0 estágio é bom para a profissionalização do aluno}

Fundamental para a integralidade de sua formação, a experiência do estágio tem sido importantíssima também na profissionalização dos alunos de jornalismo da UFG. A grande maioria dos 15 alunos que, de agosto de 1993 a dezembro de 1995, fez seu estágio em O Popular encontra-se empregada, majoritariamente, na própria Organização Jaime Câmara.

Comun. inf., v.1, n. 1, p. 120-132, jan./jun. 1998 
Que nossa experiência de estágio tem favorecido a profissionalização dos alunos, reconhece o editorial do órgão oficial do Sindicato dos Jornalistas Profissionais do Estado de Goiás:

Até agora, os estudantes sequer se perguntaram que "estágio" é esse que só atende uma parcela ínfima do alunato o que constitui um privilégio inaceitável e um elemento inclusive de desequilíbrio na competição dos recém-formados pela inserção no mercado de trabalho (Chamada, set. 1995).

Os fóruns nacionais dos estudantes de comunicação já se vêem dando conta dos resultados neomalthusianos que a inexistência de qualquer tipo de estágio vem trazendo. Têm eles lamentado que eliminando o estágio profissional "a lei não considerou a importância do acesso anterior às redações pelos estudantes, para uma passagem menos traumática ao mercado" (Proposta da Secune, 1991).

Talvez, por ter uma postura flexível na questão do estágio, o que aliás a lei lhe faculta, a corporação dos radialistas vem ocupando, em Goiânia, muitas das funções que as leis não definiram com clareza meridiana se competem ao jornalista ou ao radialista.

Procuram as escolas formar o homem, o cidadão e o profissional. A inserção de seus alunos na vida profissional não é preocupação que possam julgar lhes seja alheia.

\subsection{As limitações do estágio e a necessidade de seu aperfeiçoamento}

Em sua concepção, caracteriza-se o estágio dos alunos de jornalismo em $O$ Popular, por tratar-se de instituto perfectível, aberto à mudança. Esta característica de processo, o Departamento de Comunicação quis garantir para o programa de estágio ainda in fieri ( Of. n. 67/93 ). Prevêem suas regras definitivas que "o jornal O Popular e o Departamento de Comunicação da UFG manterão um processo de consulta permanente visando o aperfeiçoamento do programa”.

Comun. inf., v.1, n. 1, p. 120-132, jan.jun. 1998 
Este dispositivo, durante o período em que o programa de estágios esteve ativado - até $1^{\circ}$ de janeiro de 1996 -, não encontrou vontade acadêmica para sua implementação.

\section{Afirma José Marques de Melo (1991, p. 27) que}

com poucas exceções, as escolas de comunicação que forme n jornalistas estão se esclerosando rapidamente, porque não dominam a competência tecnológica do novo jornalismo e também porque enveredaram por um academicismo inconseqüente, agravado por vièses ideológicos adquiridos no período de resistência à ditadura militar e que não foram abandonados nesta conjuntura de transição democrática.

O tom das observações do autor não excluem o fato de que o estágio plenamente assumido, dentro dos limites da lei, poderia trazer, para o processo de formação, novas informações e experiências alimentadoras da reflexão teórica e das reformulações curriculares.

Neste sentido, assinala o Encontro dos Alunos de Comunicação ( ENECOS, 1994) que

as contribuições trazidas pelo estagiário podem ajudar na reelaboração dos paradigmas de produção do conhecimento acadêmico. E isto significa melhorar a qualidade do ensino e dos profissionais no mercado.

Outras Universidades também já tomam consciência da necessidade de uma maior articulação com o mercado. A UnB, em 1995, assinou convênio para iniciar no primeiro semestre de 1996, sob a forma de bolsa de trabalho, seu programa de estágio de jornalismo no Correio Brasiliense e nos meios de de comunicação dos Diários Associados.

Inserem-se essas instituições na corrente mundial das transformações dos sistemas de ensino. Escolhem hoje os projetos europeus de reforma da educação, diante das revoluções tecnológicas e do aumento das taxas de desemprego juvenil, a tradição alemã do treinamento nas oficinas - "aprendizado" como um de seus principais pilares. 


\section{Abstract}

This article, after a brief survey of international systems, presents experiences of journalism internship with students of the Federal University of Goiás within the context of brazilian legislation. Special emphasis is given to a most recent expericnce and its importance in journalism cducation.

Key words: internship; cducation; joumalism.

\section{Referências bibliográficas}

BRASIL. Decrcio n. 83.284, 13 mar. 1979.

BRASIL. Decreio n. $87.497,18$ ago 1982.

BRASIL. Decrelo-lei n. 972, 17 out. 1969 .

BRASIL. Instrução Normativa n. I - Secretaria da Administração Federal. 14 jan. 1993.

BRASIL. Lein $6.494,7 \mathrm{dc} \% 1977$

BRASIL. Lei n. $6.612,7 \mathrm{dc} \% .1978$.

CHAMADA. (Orgão de Divulgação do Sindicato dos Jornalistas Profissionais cm Goiás). Edições de fevereiro de 1994 e setembro de 1995.

DE FRETTAS. J.M.M. Admirável novo velho mundo. In: ECA-USP. Transição para a modernidade. São Paulo, 1992. p. 70s.

UNIVERSDDADE FEDERAL DE GOIÁS. Instituto de Ciências Humanas e Lciras. Departamenio de Comunicação. O fortalecimento das escolas e o fim dos estágios. In: CONGRESSO NACIONAL DE JORNAIISTAS PROFISSIONAIS, 16 , Curitiba, jun. 1976.

ENECOS. Carta aberta aos congressistas. In: Estágio em Jornalismo: Dossiè das atividades da Executiva Nacional dos Estudantes de Comunicação para a aprovação do estágio $\mathrm{cm}$ jornalismo, 1994, p. 3.

FEULLETS DU CFPF. Les "stages" dans les entreprises de presse. $\mathrm{v}$. 24, $\mathrm{n}$. 58 , p. $5-6$, printemps 1977.

KUSCINSKI, B. O first amendement e algumas tendências no ensino do jornalismo nos Estados Unidos. In: $E C A-U S P$ : Transição para a modernidade. São Paulo, 1992. p.162.

MELO, J.M. Indústria cultural, jornalismo, jornalistas. Intercom : Rev. Bras.Comunic。 São Paulo, v. 14, n. 65, p. 20-29, jul./dez. 1991.

PALÁCIOS, M. Projetos expcrimentais e mercado de trabalho: o papel das práticas laboratoriais. Signo, v. 1, n. 1. p. 13-7, out. 1993.

SECUNE. Estágio ... Qual é?. In. Estágio em Jornalismo. Op. cit. p. 2. SINDICATO DOS JORNALISTAS PROFISSIONAIS EM GOIAS. Nota de Protesto. Goiânia, 08 set.1993.

TARGINO, M.G. Projetos experimentais : um monstro aterrador? Signo. v. 2, n. 3, p. 24-33, set. 1995.

Comun. inf., v.1, n. 1, p. 120-132, jan./jun. 1998 